\title{
EXPLORING EDUCATIONAL RESEARCH DURING THE COVID-19 PANDEMIC: 2020-2021
}

\author{
Mustafa Polat ${ }^{1}$ \\ Karabuk University, Turkey
}

\begin{abstract}
Education has been one of the areas most affected by the consequences of the COVID-19 pandemic since December 2019. This bibliometric review presents "the big picture" of the knowledge production on educational research conducted between January 1, 2020, and October 31, 2021. For this purpose, the current status of the related knowledge base, the intellectual structure, and topical foci were analyzed through descriptive and bibliometric analyses using VOSviewer, Tableau, and Web of Science (WoS) analytical tools. The data set included a total of 3774 articles accessed through WoS. The findings reveal a rapidly growing global interest in educational studies related to the pandemic outbreak. However, highly skewed geographical distribution indicates an imbalance in the number of documents. Almost one-fifth of all researchers are from the USA, and authors from the top ten most productive countries published more than half of all publications. Citation and co-citation analyses shed light on the most prominent components of the related knowledge base. The intellectual structure is based on five "schools of thought" labelled "Global Perspectives to Education", "Medical Education", "Educational Psychology", "Instructional Technologies for the $21^{\text {st }}$ Century Education" and "Higher Education Studies". Similarly, topical foci of the knowledge base yielded four distinct clusters concentrated on "Digitalization of Education", "The Impacts of Psychological Variables", "Medical Studies", and "Curriculum and Instruction". The current research fronts, the lack of topical coverage and other remarkable results are discussed in order to provide a baseline for further studies.
\end{abstract}

Keywords: COVID-19, educational research, bibliometrics, citation analysis, literature review, systematic review

COVID-19, officially identified as a "pneumonia of unknown etiology" (Lu et al., 2020) and first reported by the Wuhan Municipal Health Commission to the World Health Organization [WHO] in December 2019 (WHO, 2020), has spread rapidly in a very short period of time across the world and has become a serious threat to human life (United Nations, 2020). The concept of "new normal" emerged as a new notion to express that everything which was not seen as normal until the COVID-19 period is noteworthy

\footnotetext{
${ }^{1}$ Correspondence: mustafapolat@karabuk.edu.tr
} 
in revealing the severity and power of the change experienced during this period (e.g. Cahapay, 2020).

As of February 2022, more than 410 million people have been reported infected with this virus. Despite the ongoing vaccine studies and vaccination programs to prevent the spread of the disease, highly transmissible and pathogenic SARS-CoV-2, caused nearly six million deaths worldwide since the beginning of the pandemic (WHO, 2022). Moreover, in the early stages of the pandemic, the rapid spread of the virus resulting in high death rates, as well as the frightening details in the international media, led to some dreadful effects on people's psychological and sociological domains of life (Anwar et al., 2020). Besides, the misinformation about the COVID-19, and some false statements accompanied by the contradictory practices have triggered more panic and chaos among the public. In addition to critical problems in terms of public health, the global crisis based on the outbreak of the COVID-19 pandemic has seriously affected everyday life. Next to the global health system, almost all sectors and public services across the world have suffered critically from the results of the strict regulations and restrictions of the "new normal" (Zhang, Hu \& Ji, 2020). Last but not least, the global education system is one of the most severely impacted areas by the consequences of the pandemic (e.g. OECD,2020; UNESCO, 2021).

Especially soon after WHO's declaration of a public health emergency of international concern and subsequently pandemic on March 11, 2020, more than 1.5 billion pupils registered in the different levels of schools and institutions in 117 countries were affected by partial or complete school closure measures (UNESCO, 2020). Governments' responses to this "educational disruption" depended on various variables, including their economic potential, intellectual power, technological infrastructure, and educational capacity (e.g. OECD, 2021, World Bank, 2020). Despite the educational and technological developments, which support the emergency remote teaching process, the online education platforms, the digital learning materials and tools, a great majority of young people lost out at the time of COVID-19 as it hit the most vulnerable hardest. Not only learning loss but also the negative psychological, physiological, social, and emotional impacts on students, teachers, families, and other education stakeholders reached a dramatic level.

Alternatively, the COVID-19 pandemic garnered much research interest. A significant number of studies regarding the pandemic have been carried out in all scientific areas that are directly and indirectly related to human life. Almost 190.000 scientific documents including articles, book chapters, reviews have been published in Web of Science (WoS) database and Scopus has welcomed more than 300.000 publications (Scopus, 2021; WoS, 2021) until November 2021. While clinical research has been mainly carried out on the detection, prevention, diagnosis, treatment, and vaccination process, most of the research in social sciences has focused on the multifaceted effects of the coronavirus on human life. Educational studies, which are one of the most required in this period and tightly coupled to many fields such as psychology, politics, sociology, culture, and economy, have been conducted continuously since the pandemic outbreak.

The impacts of COVID-19 on different variables such as students, teachers, administrators, educational institutions, and educational practices have been the subject of research in different aspects in the international literature. However, the literature lacks a comprehensive review of the descriptive and conceptual structural features of this knowledge base, consisting of a significant number of studies. In other words, there is a significant gap and need in this growing literature in terms of an extensive systematic review of research from different perspectives, including the current status and distribution of the studies in the context of distinctive variables, structural features of the papers, dynamics of networks and interconnections, research fronts, research trends and the contribution levels for the related knowledge production. 
This research aims to provide an inclusive and detailed overview of the global knowledge base by analyzing publications on education in the international literature at the time of COVID-19. Through the descriptive and bibliometric analyzes to be carried out within the scope of this research, the educational research carried out from January 1, 2020, to October 31, 2021, will be illuminated in various aspects, the structural and relational characteristics of the studies and research trends will be explained systematically. Below are the research questions addressed in the study:

1. What is the current status of the knowledge base on the educational studies at the time of the COVID-19 pandemic?

2. What are the most influential authors, documents, journals, universities, and countries in terms of citation impact?

3. What is the intellectual structure of the related knowledge base?

4. What topical foci attracted the greatest attention in the related knowledge base?

\section{Conceptual Framework}

Several bibliometric review studies in the field of education have been referenced while constructing the conceptual framework applied in this study (e.g. Hallinger, 2020; Kılınç \& Gümüş, 2021; Kovačević \& Hallinger, 2020). A mix-methods review procedure was adopted to cover all the surfaces of the knowledge base in the process of analysis and interpretation of the data. The conceptual framework of this review study was built on three dimensions called "the current status of the knowledgebase", "intellectual structure" and "topical foci". The first dimension has two sub-dimensions. The first one, which can be labelled as "volume and space", refers to the size and distribution of the publications in terms of different aspects such as authors, journals, universities, and countries. We called the other sub-dimension as "impact factor", and it focuses on the most influential scholars, documents, journals, universities, and countries. The first two research questions sought to shed light on the first dimension composed of two sub-dimensions.

The second dimension is "intellectual structure" which is also regarded as composition or research front. It provides information about the network among highly co-cited authors in the reference list of the knowledge base. It also brings a new perspective to the patterns of the scientific contributions from specific groups of scholars and their relations in the examined knowledge base. The third research question searches for answers for the second dimension of this review.

Last but not least, "topical foci" offers the interrelated conceptual patterns that include "hotspots" composed of overarching clusters. The third dimension could also be regarded as a kind of content analysis to document the trend topics in the related literature within a limited time period. The last dimension of the conceptual framework is based on the findings obtained through the fourth research question.

\section{Materials and Method}

This review of research employed different 'bibliometric methods', also known as "science mapping" techniques (Zupic \& Čater, 2015), to analyze meta-data associated with published educational research at the time of COVID-19 on three main dimensions mentioned previously. Bibliometric methods enable researchers to take a comprehensive picture of the "big picture" and provide detailed information about the knowledge production on a specific field or a clearly demarcated research area.

\section{Identification of Sources}

This study used the WoS database, and we followed PRISMA (Preferred Reporting Items for Systematic Reviews and Meta-Analyses) guideline (Moher et al., 
2009) in order to identify the documents in line with the purpose of the review study. The search was conducted with specific parameters as follows:

- Inclusion (Dates): January 1, 2020, to the present (October 2021)

- Inclusion (Indexes): SSCI, SCI-Expanded, A\&HCI and ESCI

- Inclusion (Document Types): Articles, reviews, and early access

- Exclusion (Document Types): commentaries, books, chapters, conference papers, and editorials

After the identification of the criteria for the review, a comprehensive keyword string that is the most frequently adopted way to find out the publications on a specific field was prepared (Kılınç \& Gümüş, 2021). The initial search produced a total of 4422 documents (Figure 1). Then, we excluded 249 publications because of the excluded types of papers mentioned above. Next, 4173 articles were examined one by one to ensure the eligibility and check their scope, whether they are related or not with the focus of this review. Examination of all the documents resulted in the exclusion of 399 irrelevant articles. At the end of this elaborative process, the data set was limited to 3774 documents.

\section{Data Extraction}

Right after the identification of the sources, bibliographic data composed of 3774 articles, early access and reviews were exported from $\mathrm{WoS}$ as an excel file for the descriptive analyses and tab-delimited text files for bibliometric analyses. The downloaded files included all the necessary "meta-data" for the systematic review, such as descriptive information about the authors, documents, journals, keywords, abstracts, cited references. Then, these text files were imported to VOSviewer, one of the most frequently used and reliable scientific analysis tools for bibliometric analysis and visualization mapping.

\section{Data Analysis}

Different types of data analyses were conducted to answer the research questions. In order to find out the answers to the first research question, the current status of the related knowledge base was analyzed through descriptive statistics conducted on the WoS analytical tools and Excel. Also, we benefitted from Tableau to create a visualization based on the findings about the geographical distribution of the countries in the database. We needed to do bibliometric analyses for the second, third and fourth questions, so we conducted VOSviewer. Regarding the second research question, citations of the authors, documents, journals, universities, and countries were analyzed to report the most influential components of the related knowledge base. As a result of these analyses, noteworthy contributions to the current knowledge production were illustrated.

Even though citation analyses for the second research question provide essential information for revealing the key authors, highly cited documents and journals or leading universities and countries, the findings are restricted by the scope of WoS from which the publications were acquired. Not only to eliminate this limitation but also to answer the third question and reveal the "schools of thought", author co-citation analysis which refers to the calculation of the frequency with which two scholars were cited together in other documents (Small, 1999) was employed. This analysis is not limited to WoS citations because it covers all the reference lists of publications. Also, co-citation analysis displays the networks among the groups of scholars who share different degrees of intellectual affinity (Hallinger \& Kullophas, 2020) because the constituents of a knowledge base such as the authors, documents or keywords and connections, which could be defined as a kind of links or relations among the items, build meaningful patterns that comprise several clusters composed of associated components (Van Eck \& Waltman, 2021). 
Finally, the topical foci of the knowledge base were identified through a keyword co-occurence analysis which provides a comprehensive perspective on the hotspots of a knowledge base and offers insight into the popular themes or concepts by identifying frequently used keywords (He, 1999). The keyword co-occurrence map generated through VOSviewer displays the trends based on the keywords, which are closely related in the dataset, and complete the missing part of the "big picture" taken by the previous analyses.

\section{Figure 1}

PRISMA flow diagram in the identification of the documents (Moher et al., 2009)
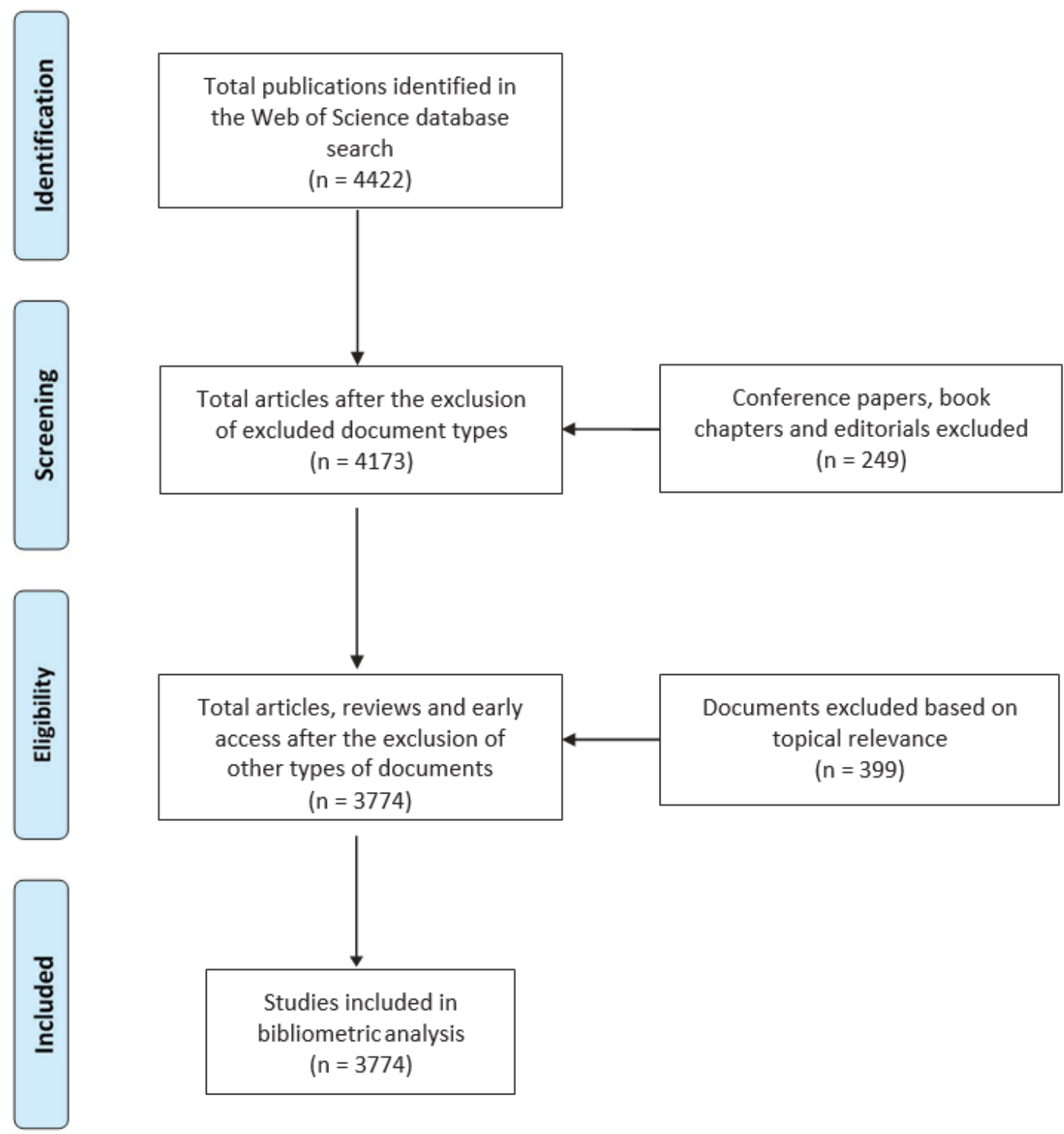

( $n=249)$

Documents excluded based on

topical relevance

( $n=399$ )

Studies included in

bibliometric analysis

( $n=3774)$

\section{Results}

In this section, findings are presented around the four research questions.

\section{The Current Status of the Knowledge Base}

A total of 3774 documents published between January 2020 - October 2021 in WoS-indexed journals are included in the analysis. While 1220 of them, which equals $32.33 \%$ of all, were published in 2020,2554 papers representing of $67.67 \%$ of the database were authored in the first ten months of 2021 . The rapid increase of $109 \%$ in the number 
of publications points out a growing global interest among scholars on the educational research in terms of the size, volume, and diversity of the publications during the COVID19 pandemic.

Next, the descriptive analysis also identified 13539 authors who contributed to the publication of 3774 articles. When the distribution of the authors was analyzed in detail, it was reported that $12807(94.59 \%)$ of them have contributed to only one article, 626 authors $(4.62 \%)$ have two papers, 84 researchers $(0.62 \%)$ have three studies, and only 22 scholars $(0.16 \%)$ have more than three. Table 1, which displays the distribution of the countries and research areas, points out the richness in diversity of the top twenty most productive scholars in this period.

Table 1

Top twenty most productive authors.

\begin{tabular}{lllcc}
\hline Authors & Country & Research Area & N & $\begin{array}{c}\text { WoS } \\
\text { Citation }\end{array}$ \\
\hline Moorhouse, B. L. & Hong Kong & English Language Education & 7 & 80 \\
Hong, J. C. & Taiwan & Engineering Education & 7 & 17 \\
Holzer, J. & Austria & Educational Psychology & 5 & 10 \\
$\begin{array}{l}\text { Lukasiewicz- } \\
\text { Wieleba, J. }\end{array}$ & Poland & Pedagogy & 5 & 8 \\
Canizares & Ecuador & Programming & 5 & 0 \\
Galarza, F. P. & & & & \\
Veletsianos, G. & Canada & Online and Digital Education & 4 & 66 \\
Obeidat, N. & Jordan & Medical Education & 4 & 50 \\
Elsalem, L. & Jordan & Medical Education & 4 & 48 \\
Gamage, K. A. A. & Scotland & Engineering Education & 4 & 32 \\
Kohnke, L. & Hong Kong & Teacher Development & 4 & 15 \\
\hline
\end{tabular}

Besides, the papers in this study were published in 1162 different journals. However, the most popular ten journals (see Table 2) welcome 723 articles that are equal to nearly one-fifth of all (19.15\%), and the most popular 50 journals host 1496 papers which mean over one-third of all (39.63\%).

Table 2

The distribution of the publications by the top ten journals.

\begin{tabular}{lcc}
\hline Journals & Country & Documents \\
\hline Journal of Chemical Education & USA & 159 \\
Sustainability & Switzerland & 122 \\
Education Sciences & Switzerland & 92 \\
Education and Information Technologies & USA & 78 \\
Frontiers in Psychology & Switzerland & 65 \\
International Journal of Environmental Research & Switzerland & 50 \\
and Public Health & & \\
Frontiers in Education & Switzerland & 43 \\
BMC Medical Education & UK & 41 \\
Arab World English Journal & Malaysia & 38 \\
International Journal of Technologies in Higher & Netherlands & 35 \\
Education & & \\
Total & & 723 \\
\hline
\end{tabular}


After that, the geographical distribution of the articles was analyzed and visualized through Tableau software. A total of 135 countries contributed to the related knowledge base. What stands out in figure 2 is the imbalance in the number of the publications by different countries. While nearly one-fifth of all authors $(19.54 \%)$ were from the USA alone, the researchers from the top ten countries constitute more than half $(51.97 \%)$. Moreover, the scholars from the top twenty countries produced $67.34 \%$ of all documents in the related knowledge base. The continents of the countries show that imbalance, too. The grey areas on the map, mostly located in Africa and South America, symbolize highly skewed distribution. The results demonstrated that 22 countries only have one publication, and more than one-third of the countries (37.03) have three or fewer studies. While Oceania, represented by only three countries, constitute 4.01\%; Africa, with 25 countries, comprises only $2.71 \%$ of all research. Likewise, North America (NA) and South America (SA) are represented by eleven countries, but researchers from NA produced $24.13 \%$ of all publications, SA published only $6.44 \%$ of all. Finally, Asia with 40 countries and Europe with 45 take the lion's share respectively $39.77 \%$ and $40.96 \%$.

\section{Figure 2}

The geographical distribution of the documents

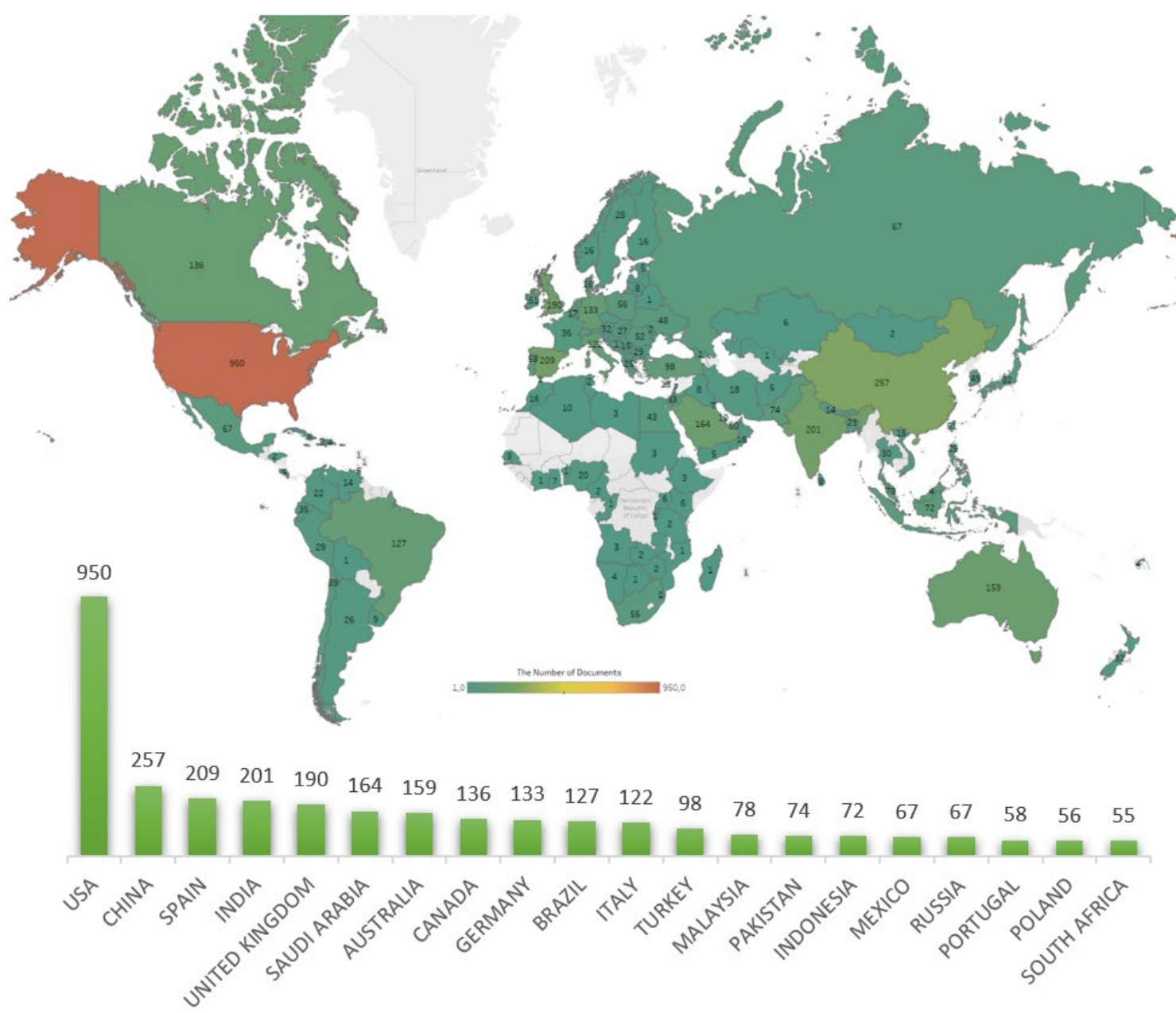

Then, we investigated the most productive universities contributing to the related knowledge base in this period through WoS analysis tool. The authors come from 4163 universities located in 135 different countries. However, 90.05\% of all universities (3749) have only three or fewer researchers who contributed to the accumulation of the knowledge base. While it's not surprising that seven of the top ten productive universities 
are located in the USA, the leading country in the geographical distribution analysis, the contributions of authors from Saudi Arabian universities are remarkable (see Table 3).

Table 3

The top ten most productive universities

\begin{tabular}{llcc}
\hline Institution & N & WoS Citation & Country \\
\hline University of California & 53 & 316 & USA \\
Harvard University & 31 & 190 & USA \\
King Saud University & 29 & 84 & Saudi Arabia \\
The University of North Carolina & 28 & 59 & USA \\
The University of Texas & 26 & 72 & USA \\
King Abdulaziz University & 25 & 71 & Saudi Arabia \\
University of Toronto & 25 & 44 & Canada \\
University of Washington & 23 & 118 & USA \\
Penn State University & 22 & 64 & USA \\
Johns Hopkins University & 19 & 52 & USA \\
\hline
\end{tabular}

\section{Influential Authors, Documents, Journals, Universities \& Countries}

In the previous part, we displayed the most productive actors of the knowledge base. Still, it doesn't always show the same structure as the most influential ones because sometimes not quantity but quality matters. It's all about the power of the impact factor, which is commonly estimated through citation analysis. Firstly, an author citation analysis was conducted to find the most prominent ones in the database. While 7199 researchers, equal to $53.17 \%$ of all scholars here, were not cited even once. The number of researchers with five or fewer citations constituted $34.64 \%$ of the total authors $(n=4690)$ contributing to the knowledge base. Table 4 displays the most highly cited researchers by the number of WoS citations. Next to the researchers focusing on medical sciences, other fields such as politics, psychology, and public administration verify the interdisciplinary structure and relations of the educational studies in this period. Finally, it is an interesting finding that all but two of the most cited researchers are on this list with only one paper, and none of the top ten most productive authors is on this list.

Table 4

The rank order of the top ten most highly cited researchers

\begin{tabular}{lccl}
\hline Author & N & WoS Citation & Research Area \\
\hline Sahu, P. & 1 & 333 & Medical curriculum \\
\hline Bao, W. & 1 & 298 & Educational Administration \\
\hline Chick, R. C. & 1 & 211 & Surgical Education \\
\hline Murphy, M. P. A. & 1 & 120 & Political Studies \\
\hline Aristovnik, A. & 1 & 112 & Public Administration \\
\hline Iyer, P. & 1 & 112 & Dentistry \\
\hline Hanrahan, J. G. & 2 & 103 & Surgical Education \\
\hline Dedeilia, A. & 1 & 103 & Medical Education \\
\hline Wang, C. & 2 & 101 & Social Psychology \\
\hline König, J. & 1 & 96 & Teacher Education \\
\hline
\end{tabular}


After the author citation analysis, we also examined the most impactful educational papers in the time of COVID-19 (see Table 5). Initial findings showed that $56.9 \%$ of the studies were not cited even once, and almost one-ninth of the documents (89.42\%) were cited five times or fewer. As explained in the previous finding, eight of the most influential authors have only one research, so it's not surprising for us to see the same scholars as the authors of the most highly cited documents. Nevertheless, it is striking that nine of the top ten most influential articles focused on higher education. The focal points of these papers are mainly about the psychological impacts of COVID-19 over university students and the digital learning-teaching process and technologies utilized at higher education as a response to the pandemic. On the other hand, only one of them published by König et al. analyzed the education and competence of teachers from different educational stages.

Table 5

The rank order of the top ten most highly cited documents

\begin{tabular}{llc}
\hline Author & \multicolumn{1}{c}{ Document } & Citations \\
\hline Sahu (2020) & $\begin{array}{l}\text { Closure of universities due to coronavirus disease } \\
\text { 2019 (COVID-19): Impact on education and mental } \\
\text { health of students and academic staff }\end{array}$ & 333 \\
\hline Bao (2020) & $\begin{array}{l}\text { COVID-19 and online teaching in higher education: } \\
\text { A case study of Peking University }\end{array}$ & 298 \\
\hline $\begin{array}{l}\text { Chick et al. } \\
\text { (2020) }\end{array}$ & $\begin{array}{l}\text { Using technology to maintain the education of } \\
\text { residents during the COVID-19 pandemic }\end{array}$ & 211 \\
\hline Murphy (2020) & $\begin{array}{l}\text { COVID-19 and emergency e-learning: Consequences } \\
\text { of the securitization of higher education for post- }\end{array}$ & 120 \\
pandemic pedagogy & 112 \\
\hline Aristovnik (2020) & $\begin{array}{l}\text { Impacts of the COVID-19 pandemic on life of higher } \\
\text { education students: A global perspective }\end{array}$ & 112 \\
\hline Iyer (2020) & $\begin{array}{l}\text { Impact of COVID-19 on dental education in the } \\
\text { United States }\end{array}$ & 103 \\
\hline $\begin{array}{l}\text { Dedeilia et al. } \\
\text { (2020) }\end{array}$ & $\begin{array}{l}\text { Medical and surgical education challenges and } \\
\text { innovations in the COVID-19 era: A systematic } \\
\text { Review }\end{array}$ & \\
\hline $\begin{array}{l}\text { König et al. } \\
\text { (2020) }\end{array}$ & $\begin{array}{l}\text { Adapting to online teaching during COVID-19 } \\
\text { school closure: Teacher education and teacher } \\
\text { competence effects among early career teachers in } \\
\text { Germany }\end{array}$ & \\
\hline $\begin{array}{l}\text { The impact of COVID-19 on anxiety in Chinese } \\
\text { university students }\end{array}$ & 93 \\
\hline Pather et al. \\
$\begin{array}{l}\text { (2020) } \\
\text { Forced disruption of anatomy education in Australia } \\
\text { and New Zealand: An acute response to the COVID- } \\
\text { 19 pandemic }\end{array}$ & 89 \\
\hline
\end{tabular}

Analysis of the journals' contributions to the related knowledge production is another component of the "big picture" reflecting the educational research in this period (see Table 6). In the findings of the first research question, the journals with the most publications were listed, but here, we also examined the order of journals by the number of citations. According to the results, while six of the journals are also among the most productive ones, the other four play active roles, although they welcome fewer documents. Moreover, the distribution of journals in terms of their topical focus showed a broader set 
of publication channels from different disciplines such as medicine (e.g. Cureus) and psychology (e.g. Frontiers in Psychology).

Table 6

The rank order of the top ten most highly cited journals

\begin{tabular}{lccc}
\hline Journal & N & WoS Citations & CPD \\
\hline Journal of Chemical Education* & 159 & 531 & 3.34 \\
Sustainability* & 122 & 491 & 4.02 \\
Cureus & 22 & 397 & 18.04 \\
International Journal of Environmental & 50 & 343 & 6.86 \\
Research and Public Health* & & & \\
Human Behavior and Emerging & 7 & 343 & 49 \\
Technologies & & & \\
Education Sciences* & 92 & 320 & 3.55 \\
Journal of Surgical Education & 16 & 266 & 16.62 \\
European Journal of Teacher Education & 10 & 266 & 26.6 \\
Frontiers in Psychology* & 65 & 233 & 3.58 \\
BMC Medical Education* & 41 & 177 & 4.32 \\
\hline
\end{tabular}

*Also listed in the most hospitable journals list

CPD: Citation per Document

We also employed citation analysis to identify the most influential institutions and to see the global distribution of the publications on educational studies at the time of COVID-19 in a different perspective (see Table 7). First of all, none of the top ten highly cited institutions was among the most productive ones except for Harvard University and The University of California. Secondly, the fact that all but two of the most influential institutions and eight of the most productive universities were located in Anglophone countries points out the existence of the "English linguistic monopoly" over the publication hotspots in the world.

Table 7

The rank order of the top ten most highly cited institutions

\begin{tabular}{lccc}
\hline Institution & N & WoS Citation & Country \\
\hline Peking University & 11 & 348 & China \\
The University of the West Indies & 7 & 341 & Jamaica \\
The University of California* & 53 & 316 & USA \\
Brooke Army Medical Center & 1 & 211 & USA \\
Harvard University* & 31 & 190 & USA \\
Swansea University & 7 & 163 & UK \\
Monash University & 18 & 157 & Australia \\
Jordan University of Science \& Technology & 14 & 145 & Jordan \\
University of Ottawa & 6 & 141 & Canada \\
Macquarie University & 6 & 140 & Australia \\
\hline
\end{tabular}

The Intellectual Structure of the Knowledge Base

We conducted the author co-citation analysis (ACA) to answer the third research question focusing on the intellectual structure of the current literature on educational 
research at the time of COVID-19. ACA not only identified the influential authors that could not be seen among the most highly cited scholars, but it also provided the essential information to illuminate and understand the complicated pattern of the relevant knowledge production. The research traditions, the disciplinary composition, and the network of the interconnections in the knowledge base could be revealed thanks to the intellectual structure analysis (Zupic and Čater, 2015).

The co-citation map (see Figure 3) that visualizes the interrelations and the similarities among the cited scholars in the database display the distinctive groups of researchers and the research interests in the knowledge base. The map consisted of 120 scholars who were cited at least 30 times. These co-cited authors were identified among the researchers from the reference lists $(n=68817)$ of all studies in this review $(n=3774$. The clusters in different colors, which could be regarded as "schools of thought" that show the commonalities in a knowledge base in the map, enable to bring the scholars together in a meaningful way (Small, 1999; Van Eck \& Waltman, 2021). Our map reveals five consistent clusters representing the distinctive schools of thought.

Although it's the smallest one, the purple cluster has a relatively central position on the map. It refers to the boundary-spanning position, which takes the charge of communicating role among the other four clusters. It is composed mostly of international organizations that work for universal policies in different areas including education, and partly of the prominent scholars studying the global issues on education.

The United Nations Educational, Scientific and Cultural Organization (UNESCO), the Organization for Economic Co-operation and Development (OECD), the United Nations (UN), the World Bank (WB) and the European Commission are the most highly co-cited international organizations in the cluster. These institutions focus on the transformation of education, which should be defined as a human right for all citizens in the $21^{\text {st }}$ century and contribute regional and global educational development from kindergarten to higher education and beyond across the world. When we looked into the individual scholars' research fields in this cluster, we discovered the hidden interrelation links between the international organizations and these scholars.

The globalization and internationalization of education, comparative education programs, the education policies and reforms around the world, the global competencies (Reimers, F. M.); the social policies, social right and transnational collaboration in education (Vanlancker, V.); global school closures, management practices (Viner, R. M.); big data in education, the future of curriculum, the global politics and practices of online learning (Williamson, B.); international assessment programs, international instruments for global policies, the innovation and transformation of educational policies and practices (Schleicher, A.); the digital learners of the 21 st century (digital natives and digital immigrants), global projects for education, new perspectives and paradigms for global education (Prensky, M.) are some of the most common research interests of the scholars in this cluster. The association and interrelations among the international organizations and the key researchers on similar research areas lift the veil of mystery. From that point of view, the purple cluster was labelled as "Global Perspectives to Education".

The blue cluster is associated with "Medical Education". This group is composed of medical researchers who study for virtual learning resources in medicine (e.g. Pather, N.); simulation (e.g. Cook, D. A.); medical curriculum (e.g. Sahu, P.); the transformation of medical education and training (e.g. Rose, S.); surgical practices (e.g. Nicola, M.); mental health and trauma (e.g. Brooks, S. K.); teaching and learning process in medical education (e.g. Longhurst, G. J.); e-learning systems in medical education, the training of medicine fellows (e.g. Ruiz, J. G.). Besides, the size of the node WHO, which is one of the most important international organizations and responsible for global public health, points out its impact factor within the school of thought labelled as medical education and in the whole map in terms of the number of co-citations. 
The third cluster, located in the upper right region of the map, is dominated by "Educational Psychology" scholars. At first glance, the leading scholars such as Bandura, who is notable for studies on social learning, cognitive learning and self-efficacy or Zimmerman, who is well known for his research on self-regulated learning, stand out on the map. In addition, the existence of scholars specifically focused on motivation (e.g. Davis, F. D., Schunk, D., Venkatesh, V.), self-regulation (e.g. Broadbent, J.), anxiety (e.g. Deci, EL), stress (e.g. Lazarus, R. S.), psychological needs of students (e.g. Ryan, R. M.), emotions in education (e.g. Pekrun, R.), academic buoyancy and resilience (Martin, A.J.) explain the meaningful interconnectedness of the nodes in the green cluster.

\section{Figure 3}

The co-citation network map ( $n=68817$ authors in the author co-citation network; threshold 30 citations; display 204 authors).

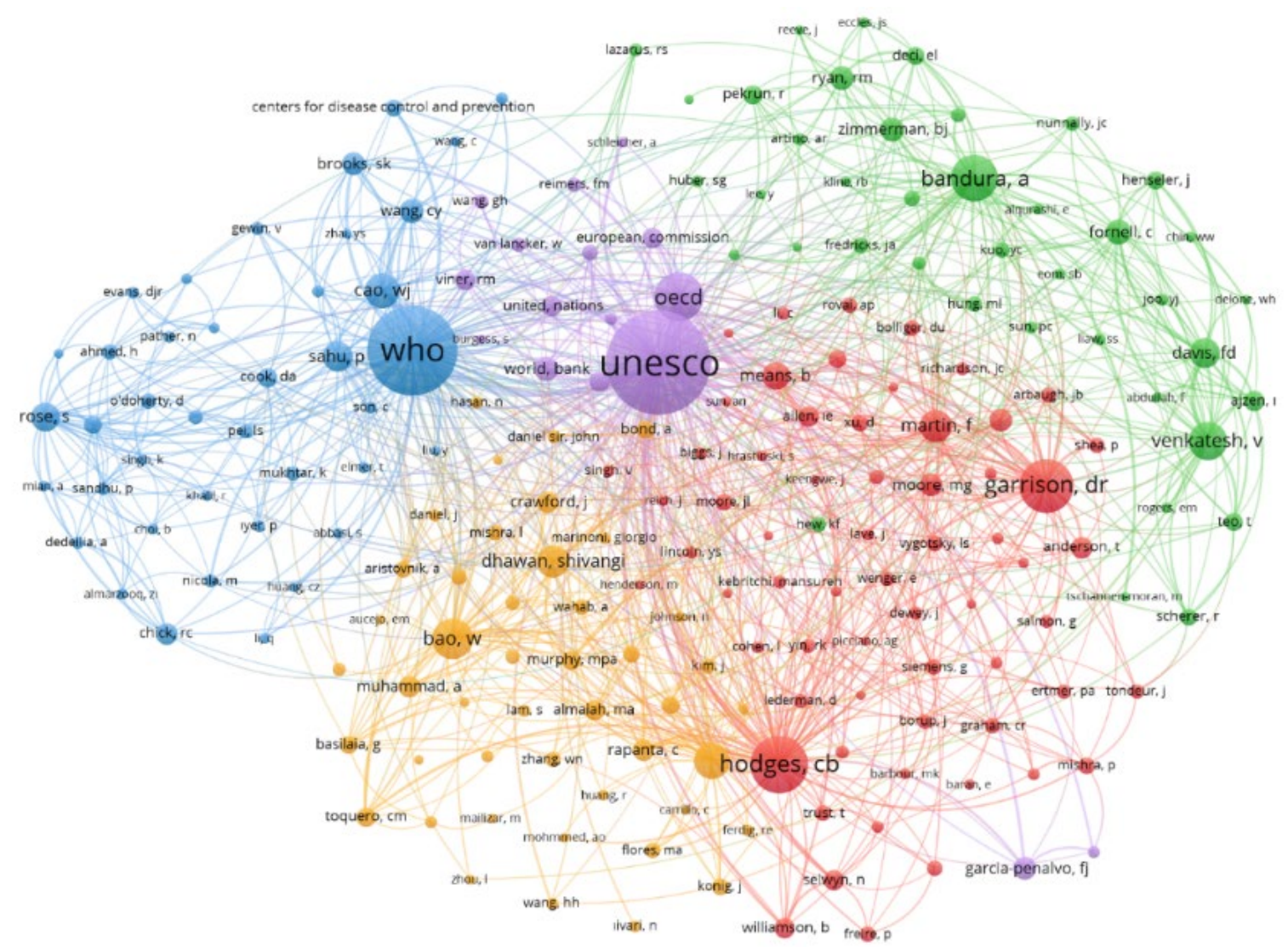

The red cluster, which is the most populated one, is distinctively composed of scholars studying "Instructional Technologies for the $21^{\text {st }}$ Century Education". It's clear that all the scholars represented with relatively bigger nodes(e.g. Hodges, C.B., Garrison, D. R., Means, B.) in the map have been studying digital technologies in education as a reform movement nearly since the first years of the new millennium. A deep dive into their portfolios shows that they started their research career with the links between the computer-based learning process and the first instructional designs of e-learning experiences. In the time of COVID-19, they primarily focus on the remote teaching and learning process, the digital transformation of materials and institutions, online learning communities, online assessment procedures, digital safety, and privacy. When we explore the other common hot topics in this cluster, the most popular ones are listed as teachers' technological pedagogical content knowledge (e.g. Mishra, P., Graham, C. R.), massive 
online open courses (e.g. Siemens, G.), engagement strategies in the online learning environment (Bolliger, D. U.), blended learning (e.g. Bernard, R. M.).

Last but not least, the orange cluster surrounded by blue, purple and red clusters included researchers concentrated on "higher education studies". Education administration and policy (e.g. Bao, W.), multiculturalism (e.g. Crawford, J.), open education systems (e.g. Bozkurt, A.), teachers' education and professional development (e.g. Flores, M. A., König, J.), the politics of education (e.g. Murphy, M.P.A.) are reported as the most co-cited authors' research fronts in the map. Also, the high density of the links, especially between the red cluster, displays the strength of affinity and the strong networks among the researchers studying digital learning and teaching technologies and those focusing on higher education.

\section{The Topical Foci of the Knowledge Base}

The final bibliometric analysis employed in this review was on the interpretation of co-occurence of keywords that is also regarded as a kind of content analysis technique (Zupic and Čater, 2015) which pinpoints the connections among the notions that exist in the keywords of publications in the related knowledgebase. While this analysis offers an understanding of the complex structure of the knowledge production, it also provides insight into the topical foci that identify the conceptual patterns. Before the analysis, a thesaurus file was prepared and imported to VOSviewer to remove unwanted repetition among keywords such as "COVID19" and "COVID-19."

First of all, the top ten most commonly used co-occurring keywords in the knowledge base are COVID-19, online learning, higher education, medical education, distance learning, pandemic, e-learning, remote teaching, online teaching, and online education. The analysis produced four distinct clusters, as can be seen in Figure 4.

- Red cluster: The digitalization of education;

- Green cluster: The impacts of psychological variables over students;

- Blue cluster: Medical studies;

- Yellow cluster: Curriculum and instruction

The biggest node located in the dead center of the co-occurence map is COVID19 as an expected result. The intense network inside and outside of the red cluster reflects the frequent relations among the notions preferred in the list of keywords of researchers. The red cluster includes similar concepts such as remote education, distance education, online education, digital education, remote teaching, distance teaching, online teaching, and digital teaching. Besides, a relatively big node representing higher education refers to the high number of studies concentrated on universities, academics, and undergraduates.

The second cluster focuses on the psychological impacts of COVID-19 on students. When we compare the negative and positive concepts related to the psychological impacts, we noted that the number of negative keywords such as psychosomatic problems, anxiety, depression, stress, trauma is much higher than the positive ones such as motivation, satisfaction.

The blue cluster is strictly dominated by the keywords related to medical studies. Clinical clerkship, dental education, medical education, medical students, nursing, residency training, surgical education, telehealth, and telemedicine are the most common ones in this cluster.

At last, the yellow cluster located at some distance from the others indicates its discrete focus on curriculum and instruction. The most apparent components of this cluster are curriculum, educational program, national curriculum, curriculum development, evaluation, instruction, instructional design, self-instruction, and computerbased instruction. 


\section{Figure 4} The keyword co-occurrence map based on 3774 WoS-indexed articles (threshold 15 co-
occurrences, display 126 keywords)

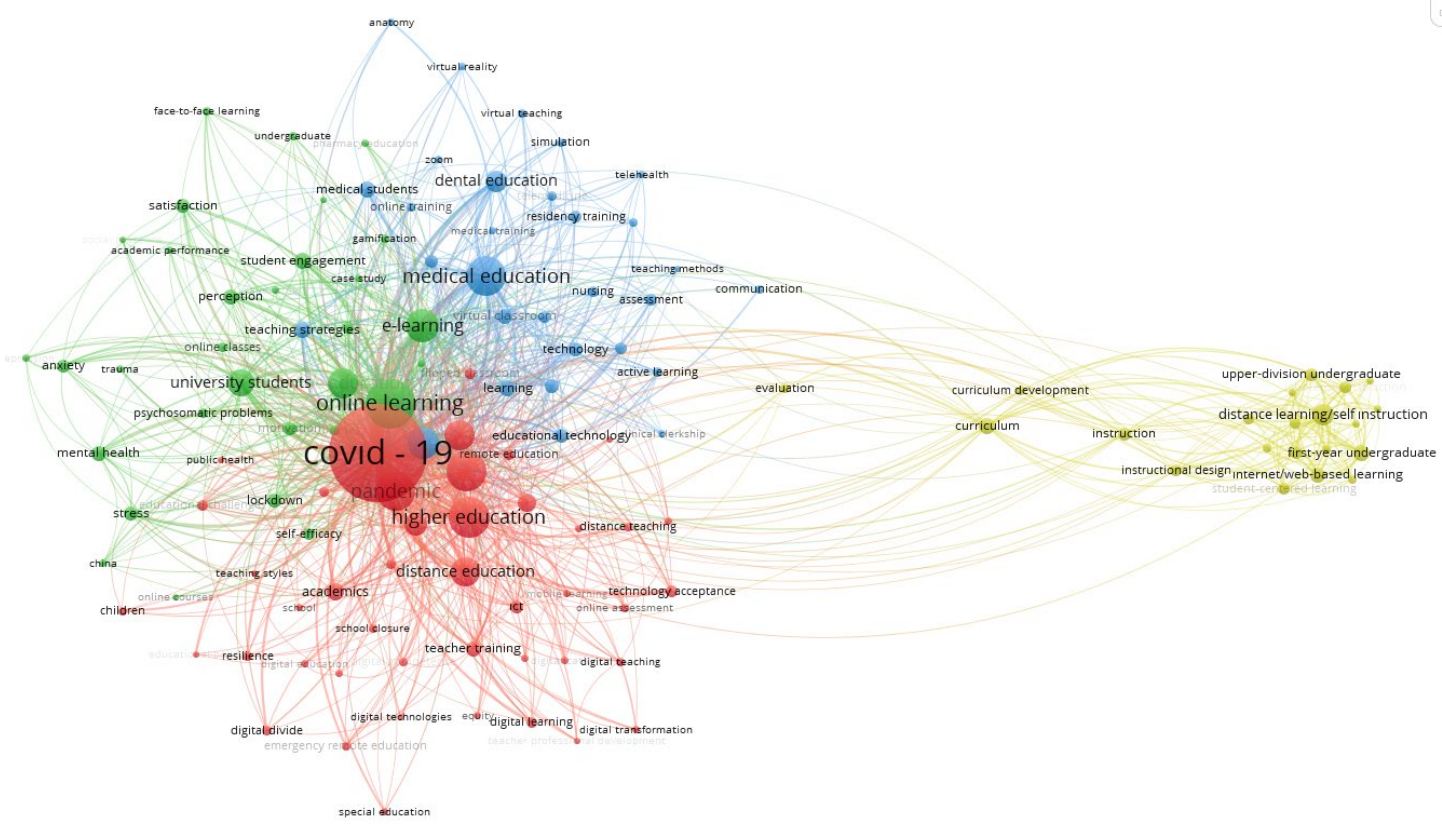

\section{Discussion}

The knowledge base on educational studies, which has been amassed since the beginning of the COVID-19 pandemic, was analyzed using science mapping that is regarded as an innovative method to understand the conceptual and intellectual structure of the related literature in this research review. A total of 3774 documents in WoSindexed journals between January 2020 and October 2021 were examined using the bibliometric and descriptive analysis, and the findings were presented in the previous section. This section discusses the limitations of this review and provides the interpretation and implications of the findings for future studies.

\section{Interpretation of the Findings}

Findings from the first research question prove that a significant amount of educational research was conducted during the pandemic. Although the database of this research is limited to only WoS indexed journals, and it does not cover the whole knowledge production, the number of articles in a limited time concludes that the field of education has accumulated a quite substantial body of knowledge. The fact that education is one of the most negatively influenced areas in the COVID-19 process has triggered researchers from different fields across the world to conduct multifaceted studies on issues directly and indirectly related to education. Especially after the global school closures, the studies carried out to eliminate the uncertainties and the challenges regarding the learning and teaching process in the emergency remote education, digital materials, online learning platforms, learning management systems have constituted an important part of this knowledge base. Next, research that aims to reveal the physiological, psychological, social, and emotional impacts of the pandemic on students also has a significant share in the rapid increase of knowledge production. Besides, the fact that the research conducted in the first ten months of 2021 has doubled the number of all studies 
conducted in 2020 can be considered as another proof for the ongoing need and interest in educational research in this period.

The geographical distribution of the studies reveals the imbalance in terms of two different dimensions. The enormous gap between the number of studies conducted in the USA and the other countries is the first imbalance. The budget allocated by the USA for the research and development, the size of the funds provided by universities and other institutions in the USA to researchers and the fact that the majority of the journals indexed in WoS are USA-based can be listed among the explanations for this situation.

The second imbalance is among the contribution levels of the countries and the regions except for the USA. As of November 2021 , there are 193 independent countries (UN, 2021), but only 135 countries contributed to the studies in this research dataset. The current status reflects an imbalance strikingly and highlights that many countries have shown no or very little interest in educational studies in this period. A significant part of the research was carried out in the anglophone countries. This result may be related to English language which is regarded as the most common lingua franca. On the other hand, the reasons why African and South American countries are very limited in this knowledge production can be explained by the development levels of these countries, the limited number of universities, researchers working in educational sciences and scientific journals in these countries.

However, in contrast to the fact that the most productive journals or universities are within very limited geography, the research capacity of the most productive or influential scholars from totally different parts of the world could be regarded as a hopeful step for the future of the educational research. Thanks to these prominent scholars, who believe that "many small make a great", the world might be able to hear and understand distinctive voices of different countries even from the "the grey areas on the map" such as emerging regions in Sub-Saharan Africa, Middle East \& North Africa, Latin America, Southeast Asia.

The findings from the citation analysis showed that almost one-ninth of the publications were either not cited at all or cited five or fewer times. It could be explained by the fact that the documents have been published relatively recently. As discussed in the first research finding, a significant majority $(67.67 \%)$ of the publications were published in the first ten months of 2021 . The fact that none of the top ten most cited documents was published in 2021 can be considered as a finding that supports the relationship between this publication year and the cumulative number of citations.

Besides, the findings about the top ten most-cited researchers and documents are considered a precursor to the fact that research on education during the COVID-19 process focuses primarily on higher education. The co-citation network map generated in the following research question also strongly supports this premise. One of the five clusters that emerged in the author co-citation analysis, which included all researchers inside and outside the database, was grouped as "Higher Education Studies". In addition, "higher education" keyword is the third most frequently used concept in the co-occurence of keywords analysis after the notions of "COVID-19" and "online education". From this point of view, it is thought-provoking that this great interest shown in higher education level research is not directed to other education levels. For example, although the sociopsychological problems arising from critical reasons such as social isolation and gaps in childcare based on the restrictions and school closures in the time of COVID-19 have affected the preschool and the special education areas the most, a relatively limited number of studies on these educational institutions can be interpreted as an important gap in the literature. In other words, the "narrow coverage zone" in the knowledge base still points out an urgent need for further scientific research on the solution of the problems in some specific education levels. 
International organizations and researchers focusing on global education issues and policies emerged as influential sources in this period. The location of the purple cluster on the map and the networks with other four clusters labelled "medical education", "educational psychology", "instructional technologies for the $21^{\text {st }}$ century education" and "higher education studies" suggests the impact power of the purple cluster called "Global Perspectives to Education" over the knowledge base. Potential global results and the implications of the studies in the database could have triggered the emergence of this pattern which presents the integral connections of different research areas.

The emergence of the "medical research" cluster can be considered a natural result of the pandemic period. The intensive interaction among the researchers in this cluster and the distribution of keywords under the blue cluster on the co-occurence map give clues to understand this "school of thought". Most of the researchers in this cluster focus on the innovative transformation of the applied teaching-learning process in the faculties of medicine, dentistry, nursing and even veterinary in the emergency remote teaching period. The compulsory orientation to the applications such as blended education, simulation, telehealth; the virtual practices even in critical areas such as surgical education or residency training and the need for revision in the curriculum of health sciences can be interpreted as exploratory factors that guide medical education research.

"Instructional Technologies for the $21^{\text {st }}$ Century Education" cluster draws great attention. The main reason behind this situation is the concentration of the whole world on online education, especially with the global school closure decisions. The world has faced many multidimensional and critical problems such as designing, developing, and evaluating online education platforms. Also, the quality of the learning-teaching process, the preparation of digital materials, and teacher training attract great attention in this period. The number of co-citations for the research carried out on the solution of all these intertwined and complex issues is higher than any other issue. The historical growth trajectory of the studies on "the digitalization of education" plays an important role in this situation. It has been a hot topic since the beginning of the $21^{\text {st }}$ century in the literature. Thus, the existence of previous multidimensional research could be considered as an important opportunity in the context of the adaptation of educational institutions to the online education process. They also offer insights for the researchers in order to determine effective education policies and practical solutions for emerging problems during the online education period.

Finally, the presence of "canonical scholars" such as Albert Bandura, Barry J. Zimmerman, or Richard M. Ryan in the green cluster on the map offers that current studies about "the impacts of psychological variables over students" are highly interrelated to issues such as self-efficacy, self-regulation, and the psychological needs of students. Moreover, based on the co-occurence map, we can also conclude that negative notions such as stress, anxiety, depression, trauma are more dominant than the positive ones such as academic resilience, academic buoyancy, or motivation.

\section{Implications}

The first implication which follows the findings of this study is about the lack of topical coverage in terms of different education levels. Both schools of thought, which represent the intellectual structure, and topical foci provide evidence that there is currently a significant number of studies in the field of higher education. On the contrary, studies focusing on preschool, primary, secondary, and high school levels are scarce. Similarly, there is a lack of research that lets us see the effects of COVID-19 on the educational stakeholders including parents, school administrators, school communities and local authorities. Further studies may shed light on these neglected areas.

We also believe that the geographical distribution of the studies in the knowledge base points out the need for research in non-western countries mentioned above. It is 
considered that the lack of knowledge production on educational studies at the time of COVID-19 can be overcome with the publication support policies of governments, the funding of international organizations working on global and regional educational studies or the projects and the international collaboration among scholars from different countries. This enables us to discover the missing pieces of the puzzle which could save us from the unknown consequences of the pandemic on education.

Three of four clusters named "the digitalization of education", "the impacts of psychological variables over students" and "medical studies" are located very close to each other on the map of topical foci, and the networks among them are so intense. The fourth cluster labelled "curriculum and instruction" is placed at some distance from the others. Moreover, only this cluster is not presented as an independent group in the map of intellectual structure. This implies that even if the number of studies on "curriculum and instruction" are fewer than other clusters, the studies under this cluster share common characteristics, and they are highly interrelated papers. From that point, we conclude that the yellow cluster provides a relatively discrete thematic center of attraction.

The intellectual structure of the current knowledge base consisted of five distinctive but logically interrelated schools of thought. In addition, four clusters that reflect the topical foci of the examined publications are consistent with the intellectual structure. This asserts that scholarly interest for educational research in this period focused on similar areas and trends. The current knowledge production reflected through the bibliometric analysis largely fails to discover some other critical issues such as unprepared parents for distance education and homeschooling; learning loss due to school closures; the professional development needs of teachers, academics and administrators; online assessment and evaluation procedures; drop-out rates; the economic costs of school closures, the reopening policies of schools and universities. It highlights the urgency for educational studies that will welcome more topical diversity.

Finally, the capacity and functionality of science mapping to construct the networks based on different bibliometric analyses let us see the current trends on educational studies during the COVID-19 pandemic. Despite its limitations, we hoped that the overall framework presented, and the findings of this bibliometric review will provide a roadmap and trigger some further studies such as meta-analysis, metasynthesis, or mixed ones which brings together qualitative and quantitative data to see details of the big picture in a holistic way.

\section{Limitations}

Firstly, although this review examined a vast database of articles on education drawn from a large proportion of all international, peer-reviewed journals indexed in WoS at the time of the pandemic, alternative qualitative methods such as content analysis can offer a deeper perspective for the understanding of the "big picture". Secondly, despite the fact that co-citation analysis breaks the limits of the extent of the publications through the inclusion of all the documents in the reference lists of articles in our dataset, the lack of other studies indexed in different databases such as Scopus, ERIC or PubMed should be overcome via an innovative technique that merges all the database on a single platform. Thirdly, the exclusion of other document types such as book chapters, conference proceedings from the database might have narrowed the scope of the results.

\section{Declaration of İnterest Statement}

No potential conflict of interest with respect to the research, authorship, and/or publication of this article was reported by the author. 


\section{About the Author}

Asst. Prof. Dr. Mustafa Polat received his first BA in the English language teaching department (2010) and the second one in international relations (2021) at Anadolu University, Turkey. He completed his $\mathrm{PhD}$ in the curriculum and instruction department at the same university (2019). He has been teaching at the tertiary level since 2012 at the School of Foreign Languages, Karabuk University, Turkey. His research interests lie in the area of curriculum, instruction, foreign language teaching, language anxieties, effective learning, and internationalization of higher education. Dr. Polat has presented a number of papers in national and international congresses, prepared European Union projects, and published several book chapters and articles in national and international scientific journals.

\section{References}

Anwar, A., Malik, M., Raees, V., \& Anwar, A. (2020). Role of mass media and Public Health Communications in the COVID-19 pandemic. Cureus, 12(9), 1-12. https:// doi.org/10.7759/cureus. 10453

Cahapay, M. B. (2020). Rethinking education in the new normal post-covid-19 era: A curriculum studies perspective. Aquademia, 4(2), 1-5. https://doi.org/10.29333/ aquademia/8315

Hallinger, P., \& Kulophas, D. (2020). The evolving knowledge base on leadership and teacher professional learning: A bibliometric analysis of the literature, 1960-2018. Professional Development in Education, 46(4), 521-540. https://doi.org/10.10 $\underline{80 / 19415257.2019 .1623287}$

Hallinger, P. (2020). Science mapping the knowledge base on educational leadership and management from the emerging regions of Asia, Africa, and Latin America, 19652018. Educational Management Administration $\Xi^{2}$ Leadership, 48(2), 209-230. https:/ /doi.org/10.1177/1741143218822772

He, Q. (1999). Knowledge discovery through co-word analysis. Library Trends 48(1), 133-159.

Kılınç, A. Ç., \& Gümüş, S. (2021). What do we know about novice school principals? A systematic review of existing international literature. Educational Management Administration $E^{2}$ Leadership, 49(1), 54-75. https://doi.org/10.1177/1741143219 $\underline{898483}$

Kovačević, J., \& Hallinger, P. (2020) Finding Europe's niche: Science mapping the knowledge base on educational leadership and management in Europe, 1960-2018. School Effectiveness and School Improvement, 31(3), 405-425. https://doi.org/10.108 o/09243453.2019.1692875

Lu, H., Stratton, C. W., \& Tang, Y. W. (2020). Outbreak of pneumonia of unknown etiology in Wuhan, China: The mystery and the miracle. Journal of Medical Virology, 92(4), 401-402. https://doi.org/10.1002/jmv.25678

Moher, D., Liberati, A., Tetzlaff, J., \& Altman, D. G. (2009). Preferred reporting items for systematic reviews and meta-analyses: The PRISMA statement. Annals of Internal Medicine, 151(4), 264-269. https://doi.org/10.7326/0003-4819-151-4$\underline{200908180-00135}$

Organization for Economic Co-operation and Development [OECD] (2020). The impact of COVID-19 on education: insights from Education at a Glance 2020. https://www. oecd.org/education/the-impact-of-covid-19-on-education-insights-education-at-aglance-2020.pdf

Organization for Economic Co-operation and Development [OECD] (2021). Country education responses to the coronavirus (COVID-19) pandemic. https://www.oecd.org /education/country-education-responses-coronavirus.htm 
Scopus. (202 1). COVID-19 search result. https://www.scopus.com/results/results. uri? sort $=$ plf-f\&src $=$ s\&sid $=8 \mathrm{e} 3107 \mathrm{ad} 6522 \mathrm{fo} 14 \mathrm{daf} 7133 \mathrm{eb04afdf} 8 \& \operatorname{sot}=\mathrm{a} \& \mathrm{sdt}=\mathrm{a} \& \mathrm{sl}$ =13\&s=ALL\%28COVID-19\%29\&origin=searchadvanced\&editSaveSearch $\equiv$ \&txGid=5a6f6674dcda383650edd8dd2121dbae

Small, H. (1999). Visualizing science by citation mapping. Journal of the American Society for Information Science, 50, 799-813. https://doi.org/10.1002/(SICI)10974571(1999)50:9<799::AID-ASI9>3.0.CO;2-G

United Nations Educational, Scientific and Cultural Organization [UNESCO] (2020). Global monitoring of school closures. https://en.unesco.org/covid 19/education response/globalcoalition

United Nations Educational, Scientific and Cultural Organization [UNESCO] (2021). COVID-19 impact on education. https://en.unesco.org/covid 19/educationresponse

United Nations [UN] (2020). COVID-19 and human rights: We are all in this together. https://www.un.org/victimsofterrorism/sites/www.un.org.victimsofterrorism/fil es/un - human rights and covid april 2020.pdf

Van Eck, N. J. \& Waltman, L. (2021). Manual for VOSviewer version 1.6.17. https:// www.vosviewer.com/documentation/Manual_VOSviewer_1.6.17.pdf

World Bank [WB] (2020). How countries are using edtech (including online learning, radio, television, texting) to support access to remote learning during the COVID19 pandemic. https://www.worldbank.org/en/topic/edutech/brief/howcountries-are-using-edtech-to-support-remote-learning-during-the-covid-19pandemic

World Health Organization [WHO] (2020). Listings of WHO's response to COVID-19. https://www.who.int/news/item/29-06-2020-covid timeline

World Health Organization [WHO] (2022). WHO coronavirus (COVID-19) dashboard. https:// covid 19.who.int/

Web of Science [WoS] (2021). COVID-19 search result. http://apps.webofknowledge. com/Search.do? product $=$ WOS $\&$ SID $=E 5 \mathrm{mrVv} 447 \mathrm{G} 5 \mathrm{tYqDXwOB} \&$ search mode $=$ GeneralSearch\&prID=ba3668c0-4161-49c6-932e-022928e295d6

Zhang, D., Hu, M., \& Ji, Q. (2020). Financial markets under the global pandemic of COVID-19. Finance Research Letters, 36, 1-6. https://doi.org/10.1016/j.frl.2020. 101528

Zupic, I., \& Čater, T. (2015). Bibliometric methods in management and organization. Organizational Research Methods, 18(3), 429-472. https://doi.org/10.1177\%2F $\underline{1094428114562629}$ 